\title{
Perspective
}

\section{How to Facilitate Social Contagion?}

\author{
Karl Blanchet* \\ Department of Clinical Research, London School of Hygiene and Tropical Medicine, London, UK
}

Received: 2 July 2013, Accepted: 15 August 2013, ePublished: 19 August 2013

\section{Abstract}

Achieving the Millennium Development Goals has proven to be a real challenge. Providing evidence on cost-effective interventions did not prove to be sufficient to secure the trust of national authorities, health care providers and patients. Introducing change in a health system requires a good understanding of the relationships between the actors of the system. Social network analysis can provide a new avenue to analyse the diffusion of innovations within a health system or a health organisation and analyse the structure and the properties of a health system. Evidence has been generated on the necessity of not only identifying the actors of a system but also qualifying the relationships between these actors.

\section{Keywords}

Social Network Analysis, Health System, Innovations

\section{Background}

The role of networks has become crucial in health care during the $21^{\text {st }}$ century with the emergence of informational and technological innovations, and with recognition from health managers that hospitals were no longer the only site of health care delivery (1). Health care providers have acknowledged the role of other actors ranging from medical and non-medical to private and public, as well as the positive impact of multiscale and multi-disciplinary network-based initiatives (1). The attributes of a person such as gender, age, socio-economic status, educational background influence a person's behaviour such as smoking habit or health seeking behaviour. But these attributes also have an impact on their relationships-their social network. These networks have in their turn an influence on how people behave. Social network analysis (SNA) focuses on the understanding of the relationships between actors and the influence of social network on individuals' decisions and the diffusion of innovations.

\section{The emergence of SNA}

Social networks are composed of a set of actors (for example, in the health sector, hospitals, doctors and patients) often called "nodes", represented by spots (2-4) that are interconnected by a set of "ties" or relationships shown by straight lines (5) (Figure 1). In order to model systems, social network researchers applied mathematical and graphical techniques to illustrate and understand the complexity of human and organisational relationships.

SNA is not new. Understanding how social networks function started in the 1930s and, in 1934 following an epidemic in a New York school, Moreno tried to analyse why the pandemic had spread so quickly amongst the pupils (6)-social network theories were used for the first time in public health. Moreno was also a pioneer to graphically represent the relationships between pupils (7). Applications of SNA in various scientific domains rapidly expanded. Between 1980 and 1990, 2196 articles on social networks were published and recorded in the Web of Knowledge ${ }^{\mathrm{SM}}$ platform. In the 1990s, and with the development of computers, there was a real enthusiasm for SNA and between 1990 and 2000, they were 11,380 articles and there was a further four-fold expansion during the decade between 2000 and 2010 (39,466 articles). The tipping point in the history of SNA was in the 2000s when SNA was labelled by the New York Times as one of the "new ideas" of 2003 and, in November of the same year, Business 2.0 described it as the "the Hottest New Technology of the 2003" (8). 'Social network' has become a very common term in the $21^{\text {st }}$ Century with the emergence of vast virtual social networks through the development of the internet, mobile and smart phones. In November 2012, at the Global Symposium on Health Systems Research in Beijing, SNA had become a popular concept and the scientific study of social networks has been recognised as a robust methodology to help health service managers and policy makers make informed decisions on how to introduce changes and innovations in a health system.

\section{The role of social network analysis in social science}

In social sciences, SNA has proven to be helpful in understanding the nature of relations between actors within a system and how these relationships influence the structure of a system (9). In ecology, studies using SNA have focused on the relationships between the different species in a food web and how the disappearance of one species could have major impact on other species connected in the same food web (10). Social network theories have also been very useful when studying interactions between ecological systems and communities $(6,11)$. Academics have found that there is a relationship between the type of links between actors (i.e. bonding between actors of the system or bridging links with other systems) and the resilience of social-ecological systems $(12,13)$. In organisational studies,

^Corresponding author: Karl Blanchet; Email: Karl.blanchet@lshtm.ac.uk 


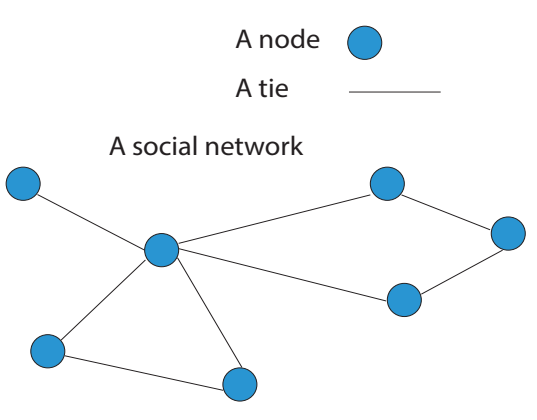

Figure 1. The graphic representation

scholars have shown that social networks determine the level of cooperation between individuals: in other words, individuals tend to collaborate more easily with their direct neighbours (14). SNA researchers have also shown that, while individuals are connected with a limited number of people, all people in the world are indirectly connected by a number of ties that on average does not exceed "six degrees" (15). SNA showed that social connections represent a social capital that provides, for example, the power to find jobs (16) or finalise business contracts (17). Individuals connected through a social network tend to have similar beliefs and values (18). Social networks theory has also helped researchers to understand the management and diffusion of knowledge (19), group behaviour, group dynamics, and organisational structures (20).

\section{Applications in public health}

Health care providers have recognised the role of other actors, medical and non-medical, private and public, as well as the positive impact of multi-scale and multi-disciplinary networkbased initiatives (21). In health systems research, networks have implicitly been at the heart of health systems (22). In their own definition of a health system, Kohn et al. (23) made even more explicit how social networks play a crucial role. They saw a health system as a network of actors who aimed to provide health care: "In health care, a system can be an integrated delivery system, a centrally owned multihospital system, or a virtual system comprised of many different partners over a wide geographical area" (23).

SNA has already been applied in public health to analyse transmission mode of HIV/AIDS (24), the sharing of needles amongst a network of drug users (25), information seeking by patients on health facilities and treatments (26), health service management (27), health systems research (28), and knowledge transfer and exchange (29). The application of SNA has been very productive to understand disease transmission (30). In the case of HIV/AIDS or sexually transmitted diseases, SNA helps predict how a disease outbreak is based on the nature of relationships between the members of a community (31). Several studies focused on the link between the number and quality of social relationships and morbidity $(32,33)$. A study showed that child mortality decreased with increased social network of the mother (34). However, much more can be done to understand individual or collective behaviour through the study of social networks as explained in the following sections.

In terms of social contagion, SNA tells us that an innovation is usually adopted by a small number of people in the network, the early adopters (35), and is then promoted by opinion leaders, people who are at the centre of the network and have the capacity to reach people located at different levels of the network (36). Opinion leaders will contaminate their own peers and by homophily, contagion will spread amongst peers $(37,38)$.

The optimal structure of a social network

Mathematicians and software developers have elaborated a series of algorithms and software packages that can be used by researchers to identify the characteristics of networks' members and, characterise the structure of the social networks (39-41). Three types of networks have been identified by social scientists: ego-centric, socio-centric and open-system networks (42). Ego-centric networks are networks where connections relate to a single individual (e.g. list of my best friends). Socio-centric networks are networks within a well defined social environment such the relationships between health professionals within the hospital. Open system networks have no clear limits and could be extended as long as we find more connections (e.g. relationships between public health universities in the world). The analysis of social networks could be conducted at the level of every node or member of the network or the whole network level.

At the individual level, scientists were interested to understand why two individuals were connected to each other. They discovered that people who were geographically close to each other or visited the same place at the same time were more likely to establish a relationship (43), which is described in literature as propinquity or geographical proximity (44). Homophily is another characteristic of individuals studied by SNA: people tend to have relationships with people who have similar characteristics as themselves (45). This means that the composition of a personal social network reflects the characteristics of that person and those ideas that are communicated within a network are consensual rather than innovative (46). The implication of homophily is that the introduction of a new management system or a new drug for example into a health system needs to come from an actor who stands outside the network.

At the whole network level, studies focused on measuring the various properties of the network: density and structural holes to analyse the number of ties between nodes, centrality to identify the nodes that have more ties than others, and distance that measures the number of ties separating two different nodes. For example, it was shown that dense networks facilitate circulation of information (38) although too dense networks can become less innovative (47). A centralised network present the advantage of being an efficient model when introducing an innovation: only a low number of individuals need to be contacted for promoting an innovation. It may also result in bottlenecks if the individuals at the centre of the network block the diffusion (37). In terms of distance, the diffusion of innovations can be accelerated when the distance between actors within the network is short (42).

Understanding the properties of the network can help predict the pace of diffusion of an innovation within a network and shape the most efficient strategy to introduce a new idea or technology. For example, the structure of a network can be described in terms of centrality. Freeman showed that the network structure with the highest centralisation degree is the star network (Figure 2) (48).

In terms of the general structure of a network, two properties were particularly used in SNA: cohesion and shape (49). Cohesion defines the number of connections within the network and includes sub-properties such as density and fragmentation. Shape relates to the overall distribution of ties and distinguishes the core actors from the peripheral ones (50). In terms of actors, their position provides indications of how actors get access to information. For example, Padgett and Ansell (51) showed that 
Table 1. Definition of key network measures

\begin{tabular}{|ll|}
\hline Characteristic & Measure \\
\hline Betweenness & $\begin{array}{l}\text { Betweenness is a measure that indicates how much a node is located in the path between other } \\
\text { actors or how much a node connects with other nodes (52). }\end{array}$ \\
The degree of centrality represents the number of ties a node has (53). If a node has many \\
ties compared to its actors, this indicates that the node has a central position in the network. \\
Centrality can also characterise the shape of a whole network.
\end{tabular}

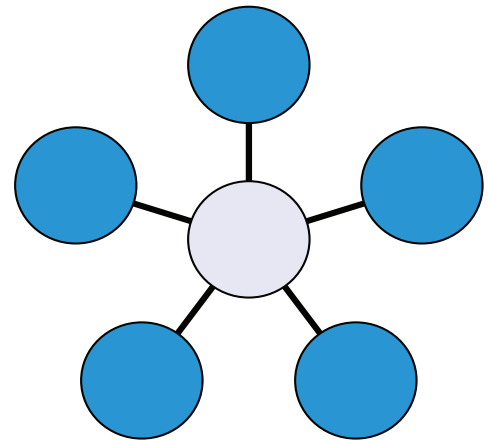

Figure 2. The star network

the power of the Medici family in the $15^{\text {th }}$ century could be attributed to the control of information flows gained as a result of their central position in the Italian business community. Centrality, reachability and betweenness are the most wellknown properties of node-related properties. The definitions of these quantitative measures are presented in Table 1.

Rogers and Kincaid (54) discovered that, in Korea, the village that had the highest compliance of contraceptives amongst women was the village that had the highest degree of centrality and where opinion leaders were imitated by women at the periphery of the network. There is also some evidence that the level of density of a network influences the circulation of information between its members: the denser the network, the quicker information spreads $(28,38,55)$. However, it has also been shown that a dense network may be an obstacle to introduce new ideas into a network (56). Identifying the optimal network structure for system performance and diffusion of innovations is probably the next task for social network researchers.

\section{Limitations}

SNA has mainly focused on the relationship between actors but only a limited number of studies have focused on the characteristics of the relationship, for example the strength of the link between actors or the type of information circulated between actors. There is also limited research on the link between the structure of the network and the performance of the network (e.g. the impact of social network on the resilience of health systems). A third limitation of SNA is to define the borders of the network. Researchers have difficulty to justify the borders of the network under study as additional sub-networks can often be identified.

\section{How to get started}

There are numerous books and papers describing the various methods that can be used in SNA (20,41,46,57-59). These texts explain the various methods used to collect and analyse data and elaborate the measures used to calculate the properties of social networks. Network studies draw extensively on survey and questionnaire data. Researchers can decide on the type of relationship to be studied (e.g. circulation of information, friendship, collaboration) and the persons who will be interviewed. Data can be collected at every level focusing on the direct environment of the researcher: who is collaborating with whom, who is friend with whom? The results can be recorded in an Excel file. Network measures can be calculated and networks drawn using software packages such as UCINET (60). A free online course is also available on Coursera (www.coursera. org) and regular workshops are organised by the International Network for Social Network Analysis (www.insna.org).

Ethical issues

Not applicable.

\section{Competing interests}

The author declares no competing interests.

Author's contribution

$\mathrm{KB}$ is the single author of the manuscript.

\section{References}

1. Thompson GN, Estabrooks CA, Degner LF. Clarifying the concepts in knowledge transfer: a literature review. J Adv Nurs 2006; 53: 691-701.

2. Marsden PV. Network Data and Measurement. Annu Rev Sociol 1990; 16: 435-63.

3. Degenne A, Forsé M. Introducing Social Networks. London: Sage Publications; 1999.

4. Borgatti SP, Foster PC. The Network Paradigm in Organizational Research: A Review and Typology. J Manage 2003; 29: 991-1013.

5. Batley R, Larbi G. Changing views of the role of the Government. In The Changing role of Government: The Reform of Public Services in Developing Countries. Houndsmill, Basingstoke, Hampshire: Palgrave Macmillan; 2004.

6. Moreno JL. Who shall survive? foundations of sociometry, group psychotherapy, and sociodrama. Beacon, NY: Beacon House, Inc; 1934. 7. Folke C, Hahn P, Olsson P, Norberg J. Adaptive governance of socioecological systems. Annu Rev Environ Resour 2005; 30: 441-73. 
8. Gertner J. The 3rd annual year of ideas. New York Times. [serial on the Internet]. 2003 Dec 14. [cited 2013 Aug 10]; Available from: http:// www.nytimes.com/2003/12/14/magazine/2003-the-3rd-annual-year-inideas-gps-art.html

9. Webb C, Bodin O. A network perspective on modularity and control of flow in robust systems. In: Norberg J, Cumming GS, editors. Complexity theory for a sustainable future. New York: Columbia Press; 2008. p. 85-118.

10. Dunne JA, Williams RJ. Cascading extensions and community collapse in model food webs. Mar Ecol Prog Ser 2009; 273: 291-302.

11. Spillane JP. Distributed leadership. San Francisco, CA: JosseyBass; 2006.

12. Burt RS. The Social Capital of Structural Holes. In: Guillen MF, Collins R, England P, Meyer M, editors. The New Economic Sociology: Developments in an Emerging Field. New York: Russell Sage Foundation; 2003. p. $148-89$.

13. Newman L, Dale A. Network Structure, Diversity, and Proactive Resilience Building: a Response to Tompkins and Adger. Ecology and Society 2005; 10: $r 2$.

14. Nowak MA. Five rules for the evolution of cooperation. Science 2006; 314: 1560-3.

15. Watts DJ, Strogatz SH. Collective dynamics of "small world" networks. Nature 1998; 393: 440-2.

16. McGuire GM. Gender, race, ethnicity, and networks: The factors affecting the status of employees' network members. Work Occupation 2000; 27: 500-23.

17. Uzzi B, Gillespie JJ. Knowledge spillover in corporate financing networks: Embeddedness and the firms debt performance. Strategic Management Journal 2002; 23: 595-618.

18. Kiesler S, Cummings JN. What do we know about proximity and distance in work groups? A legacy of research, distributed work. Cambridge, MA: MIT Press; 2002.

19. Borgatti SP, Cross R. A relational view of information seeking and learning in social networks. Manage Sci 2003; 49: 432-45.

20. Wasserman S, Faust K. Social network analysis: methods and applications. Cambridge: Cambridge University Press; 1994.

21. Thompson GN, Estabrooks CA, Degner LF. Clarifying the concepts in knowledge transfer: a literature review. J Adv Nurs 2006; 53: 691-701. 22. World Health Organization. Strengthening health systems: what works? Geneva: Alliance for Health Policy and Systems Research, World Health Organisation, 2010.

23. Kohn LT, Corrigan J, Donaldson MS. To err is human: building a safer health system. Washington D.C.: Institute of Medicine; 2000.

24. Klovdahl AS. Social networks and the spread of of infectious diseases: The Aids example. Soc Sci Med 1985; 21: 1203-16.

25. Latkin CA, Donnell D, Metzger D, Sherman S, Aramrattna A, DavisVogel A, et al. The efficacy of a network intervention to reduce HIV risk behaviors among drug users and risk partners in Chiang Mai, Thailand and Philadelphia, USA. Soc Sci Med 2009; 68: 740-8.

26. Kelner M, Wellman B. Health care and consumer choice: medical and alternative therapies. Soc Sci Med 1997; 45: 203-12.

27. Wickizer TM, von Korff M, Cheadle A, Maeser J, Wagner EH, Pearson D. Activating communities for health promotion: a process evaluation method. Am J Public Health 1993; 83: 561-7.

28. Blanchet $K$, James $P$. The role of social networks in the governance of health systems: the case of eye care systems in Ghana. Health Policy Plan 2013; 28: 143-56.

29. Wonodi CB, Privor-Dumm L, Aina M, Pate AM, Reis R, Gadhoke $P$, et al. Using social network analysis to examine the decision-making process on new vaccine introduction in Nigeria. Health Policy Plan 2012; 27: ii27-38.

30. Rothenberg RB, Sterk C, Toomey KE, Potterat JJ, Johnson D, Schrader $\mathrm{M}$, et al. Using social network and ethnographic tools to evaluate syphilis transmission. Am Sex Transm Dis Assoc 1998; 25 : 154-60.

31. Wohlfeiler D. Structural and environmental HIV prevention for gay and bisexual men. AIDS 2000; 14: S52-6.

32. Kaplan BH, Cassel JC, Gore S. Social support and health. Med Care 1977; 15: 47-57.

33. Cassel J. The contribution of the social environment to host resistance. Am J Epidemiol 1976; 104: 107-23.

34. Adams AM, Madhavan S, Simon D. Women's social networks and child survival in Mali. Soc Sci Med 2002; 54: 165-78.

35. Burt RS. Social contagion and innovation: cohesion versus structural equivalence. Am J of Soc 1987; 92: 1287-355.

36. Valente TW, Pumpuang P. Identifying opinion leaders to promote behavior change. Health Educ Behav 2007; 34: 881-96.

37. Rogers EM. Diffusion of Innovations. $5^{\text {th }}$ ed. New York: The Free Press; 1995.

38. Valente TW. Network models of the diffusion of innovations. Cresskill, NJ: Hampton Press; 1995.

39. Borgatti SP, Everett MG, Freeman LC. UCINET 6.0 Version 1.00. Natick: Analytic Technologies; 1999.

40. Lebel L, Garden P, Imamura M. The politics of scale, position and place in the management of water resources in the Mekong region. Ecology and Society 2005; 10: 18.

41. Borgatti SP, Mehra A, Brass DJ, Labianca G. Network Analysis in the Social Sciences. Science 2009; 323: 892-5.

42. Kadushin C. Understanding social networks: Theories, concepts and findings. New York: Oxford University Press; 2012.

43. Feld SL, Carter WC. Foci of activities as changing contexts for friendship. In: Adams RG, Allan G, editors. Placing friendship in context. Cambridge: Cambridge University Press; 1998.

44. Pattison PE, Robins GL. Neighbourhood-based models for social networks. Sociol Methodol 2002; 32: 301-37.

45. McPherson M, Smith-Lovin L, Cook JM. Birds of a feather: Homophily in social networks. Annu Rev Sociol 2001; 27: 415-44.

46. Valente TW. Social networks and health: Models, methods and applications. Oxford: Oxford University Press; 2010.

47. Oh H, Chung M, Labianca G. Group social capital and group effectiveness: the role of informal socializing ties. Acad Manage $J$ 2004; 47: 860-75.

48. Freeman LC. Centrality in social networks I. conceptual clarification. Soc Networks 1979; 1: 215-39.

49. Borgatti SP, Foster PC. The Network Paradigm in Organizational Research: A Review and Typology. J Manage 2003; 29: 991-1013.

50. Borgatti SP, Everett MG, Shirey P. LS sets, lambda sets and other cohesive subsets. Soc Networks 1990; 2: 337-57.

51. Padgett JF, Ansell C. Robust Action and the Rise of the Medici, 14001434. Am J of Sociol 1993; 98: 1259-319.

52. Freeman LC. A Set of Measures of Centrality Based on Betweenness. Sociometry 1977; 40: 35-41.

53. Freeman MV. Role of inside Counsel. Harv Bus Rev 1984; 62: 216.

54. Rogers EM, Kincaid DL. Communication Networks: Toward a New Paradigm for Research. New York: Free Press; 1981.

55. Blanchet K, Girois S, Urseau I, Smerdon C, Drouet Y, Jama A. Physical rehabilitation in post-conflict settings: analysis of public policy and stakeholder networks. Disabil Rehabil 2013.

56. Valente TW, Chou CP, Pentz MA. Community coalitions as a system: effects of network change on adoption of evidence-based substance abuse prevention. Am J Public Health 2007; 97: 880-6.

57. Blanchet K, James P. How to do (or not to do) ... a social network analysis in health systems research. Health Policy Plann 2012; 27 : 438-46.

58. Carrington J, Scott J, Wasserman S. Models and methods in social network analysis. New York: Cambridge University Press; 2005.

59. Kadushin C. Understanding social network: Theories, concepts and findings: Oxford: Oxford University Press; 2012.

60. Borgatti SP, Everret MG, Freeman LC. Ucinet 6 for Windows: Software for social network analysis. Harvard: Analytic Technologies; 2002. 